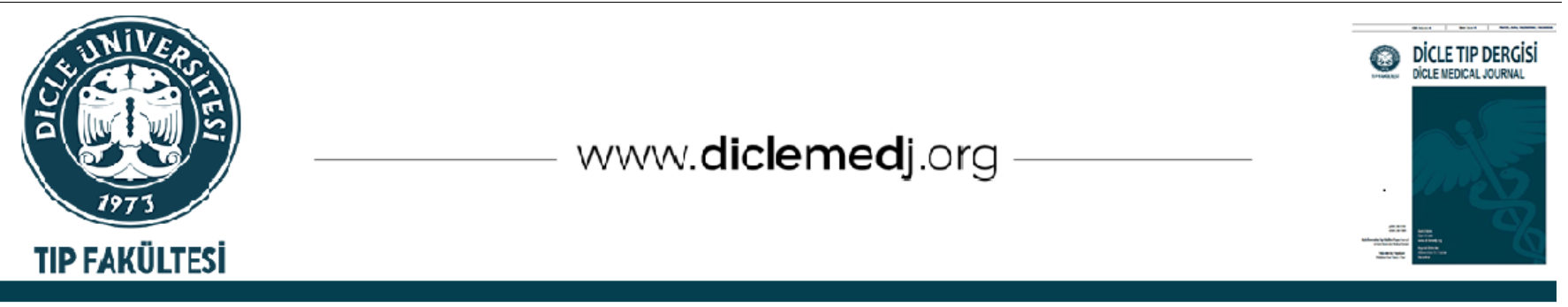

Derleme / Review

\title{
COVID-19 Pandemisi-Anestezi Yönetimi
}

\section{Zeynep Baysal Yıldırım iD 1}

1 Dicle Üniversitesi Tıp Fakültesi Anesteziyoloji ve Reanimasyon AD Diyarbakır, Türkiye

Geliş: 22.09.2021; Kabul Tarihi: 29.09.2021

\section{Öz}

Coronavirüs kaynaklı COVID-19 hastalığı Dünya Sağlık Örgütü (WHO) tarafından 11 Mart 2020 tarihinde ise pandemi olarak ilan edilmiştir. Hastalığın ilanı ile birlikte Anesteziyoloji ve Reanimasyon uygulamaları için de uluslararası ve ulusal birçok kurum, dernek veya saygın bilimsel platformlarda hastalığın tanısı, korunma, şüpheli veya kesin tanılı hastalarda izlenecek algoritmalar ile ilgili rehberler düzenlenmeye başlanmıştır. Dünya genelinde virüs hakkındaki bilgi ve tecrübeler arttıkça rehberler güncellenmeye devam etmektedir. Bu derlemede, COVID-19 kuşkulu veya kesin tanısı olan hastaların anestezi yönetiminden söz edilmiştir.

Anahtar kelimeler: COVID-19 -19, Anestezi yönetimi, Ameliyathane

\section{COVID-19 Pandemic-Anesthesia Management}

\begin{abstract}
The coronavirus-induced COVID-19 disease was declared a pandemic by the World Health Organization (WHO) on March 11,2020 . With the announcement of the disease, guidelines for the diagnosis of the disease, prevention, algorithms to be followed in patients with suspected or definitive diagnosis have begun to be prepared in many international and national institutions, associations or reputable scientific platforms for anesthesia and reanimation practices. The guides continue to be updated as knowledge and experience about the virus increase around the world. In this review, anesthesia of patients with suspected or definite diagnosis of COVID-19 management has been mentioned.
\end{abstract}

Key words: COVID-19, Anesthetic management, Operating room.

DOI: 10.5798/dicletip.1005196

Yazışma Adresi / Correspondence: Zeynep Baysal Yıldırım, Dicle Üniversitesi Tıp Fakültesi Anesteziyoloji ve Reanimasyon AD Diyarbakır, Türkiye e-mail: zbaysal2003@yahoo.com 


\section{GíRiş}

Coronavirus hastalı̆̆ 2019 (COVID-19), Çin'in Hubei eyaletine bağlı Wuhan şehrinde bir pnömoni olarak başlamış ve 2019'un sonunda Çin Hastalık Kontrol ve Önleme Merkezleri (Çin CDC) tarafından araştırılarak yeni bir koronavirüs, SARS- CoV-2 tanımlandı. Bu COVID-19'un etken patojeniydi.. Ocak 2020'nin sonunda Çin CDC, SARS-CoV-2'nin insandan insana bulaşmayı doğruladı; asemptomatik SARSCoV-2 taşıyıcılarıyla yakın temas da hastalığın bulaștığı söylendi ${ }^{1}$.

Çin'deki "Bahar Şenliği Rush" nedeniyle, virüs hızla Çin'in diğer illerine ve sonrasında dünya yayıldı². Dünya Sağlık Örgütü (WHO), 11 Mart'ta COVID-19'u küresel bir salgın olarak ilan etti.

Türkiye'de aynı zamanda pandemi için gerekli önlemler alınmaya başlandı. Bunlardan bazıları elektif cerrahi prosedürlerin iptal edilmesi, acil durumlar dişında sağlık hizmetlerinin durdurulması gibi gerekli önlemlerdi.

Virüsün bu hızlı ve küresel yayılmasının ardından, COVID-19 hastalarının yönetimi ve aerosol oluşturan işlemlerde (entübasyon, ekstübasyon, hava yolu aspirasyonu) enfeksiyon riski hakkında bilgi sağlamak için ulusal/uluslararası anestezi dernekleri tarafından kılavuzlar hazırlanmıştır4.

\section{Ameliyathane/Anestezi Yönetimi}

COVID-19 ile enfekte olan hastaların mümkünse elektif ameliyatlar ertelenmelidir ${ }^{4}$. COVID-19 olan hasta ameliyathaneye gelmeden organizasyonu yapılmalı, anestezi makinası hazırlanmalıdır 5 .

COVID-19 pandemisinde ilk tedbir sağlık çalışanlarını korumaktır. Bu sebeple Kişisel Korunma Ekipmanları (KKE); cerrahi formalarının üzerine giydikleri su geçirmeyen tulum, tüm ayağı örten deliksiz terlik ya da mümkünse steril edilebilir lastik çizme ve eldivenin ardından, N95 veya FFP2/FFP3 tipi maskeler, gözlük, yüz siperliği, cerrahi önlük ve ikinci eldiven giymeleri gerekmektedir. Kişisel koruyucu ekipmanların giyip çıkarma konusunda kullanımı ile ilgili bilgi eksiklerinin olduğu ve yanlış kullanımına bağlı bulaş riski gibi sorunlar nedeniyle korku yaşandığı kullanıcılar tarafından ifade edilmektedir ${ }^{5}$. Bu sebeple, Türkiye'de Sağlık Bakanlığı'nın yayınlamış olduğu "COVID-19 Kişisel Koruyucu Ekipman Giyme Çıkarma Talimatı'na"6 bağlı kalarak kurumumuzda tüm anestezi, ameliyathane personeli için bu eğitimler aralıklı olarak yapılmaktadır.

\section{Ameliyathane Planması}

Şüpheli ve tanı almış COVID-19 hastaların operasyonu için, ameliyathanenin, ayrı giriş çıkışı olan farklı bir ameliyathane tahsis edilmelidir ${ }^{5}$. Virüs bulaşını en aza indirmek için hastanın peroperatif dönemi (pre-intrapostoperatif) aynı ameliyat odasında gerçekleșmelidir ${ }^{5,7}$. Ameliyathane odalarında özellikle negatif basınçlı sistem ve entegre yüksek verimli hava filtresine (HEPA) sahip kendi havalandırma sistemi bulunması virüs yayılımı en aza indirgeyecektir. Operasyon esnasında kapılar mutlaka kapalı tutulmalıdır8. Ameliyat sırasında kişi sayısı (anestezi/cerrahi/ameliyathane), odaya giriş ve çıkışlar mümkün olduğunca az olmalıdır ${ }^{9}$. Tüm ekip takılarını (saat vb) iş yerinde kullanmamalı; cep telefonu vb. malzemeleri koruyucu (plastik kılıf) içinde saklanmalıdır5.

\section{Preoperatif Değerlendirme;}

Değerlendirmeyi yapan doktor, KKE kullanmalıdır. Hastaların ayrıntılı preoperatif değerlendirmesi yapılmalıdır. Operasyonu planlanan hastalara öncelikle COVID-19 için PCR testi yapılmalı, gerekli görülürse Toraks Bilgisayarlı Tomografisi (BT) istenilmelidir. Şüpheli veya pozitif olan hastalardan 
enfeksiyon ve gögüs hastalıkları görüşü alınmaktadır. Poliklinikte operasyon riski ve COVID-19 bulaşma riski hakkında ayrıntılı bilgi verilmeli ve hastalardan bununla ilgili aydınlatılmış onam alınmalıdır. Tüm hastalara Covid-19 pozitif gibi yaklaşılmalıdır.

\section{İntraoperatif Dönem;}

COVID-19 hastalarında bulaş riskini azaltmak için genel anestezi uygulamalarında endotrekeal entübasyon önerilmektedir.

Anestezi makinasina bağlanan solunum devresinin ekspirasyon ve inspirasyon çıkışına anestezi indüksiyonundan önce, nemlendirme özelliği olan bakteri/virüs filtresi eklenmeli, her hastadan sonra filtre ve anestezi cihazındaki soda-lime değiştirilmelidir. Tek kullanımlık hava yolu ekipmanı kullanılmalıdır ${ }^{5}$.

Preoksijenizasyon yüz maskesi aerosol yaymamak için şeffaf bir örtü altında uygulanmaktadır. Hızlı seri indüksiyonda mutlaka yeterli kas gevşemesi sağlanmalıdır. Hastalara maskeyle ventilasyondan kaçınılmalıdır. Endotrakeal entübasyon işleminde videolaringoskop kullanılması önerilmektedir ${ }^{10}$. Videolaringoskop ile hastanın ağız içini görüntülemek için eğilmeden, klemplenmiş tüple entübasyonu yapılmaktadır. Eğer zor entübasyon ihtimali varsa tüp içine kllavuz tel yerleştirilmelidir. Endotrakeal tüp ağız kenarı yaklaşık olarak 20-23 cm derinlikte kaf şişirilir. Tüp klempi kaldırılır. Endotrakeal tüpün yeri kapnografi ve göğüs hareketleri ile teyid edilir ${ }^{11}$. Ameliyat boyunca solunum devresi sıkı kontrol edilmelidir. Solunum devresinin hastan ayrilması gereken durumlarda mutlaka endotrakeal tüp klemplenmelidir. Viral aerosol dağılımını azaltmak için mevcut ise kapalı aspirasyon sistemleri tavsiye edilmektedir. Mümkün olamadığı durumlarda aspirasyon uygulamaları minimumda tutulmaktadır. Nasogastrik tüp yerleştirilmesi önerilmemektedir ${ }^{11}$. Hastanın kan ve salgıları ile bulaş olan tekrar kullanılabileceği düşünülen malzemeler dezenfeksiyona gönderilmeli, tek kullanımlık olanlar tıbbi atık kutusuna atılmalıdır.

Anestezi idamesi hastanın hemo dinamik durumuna göre göre inhalasyon veya total intrave $\neg$ nöz anestezi yapılarak devam ettirilir. COVID-19 hastalarda intraoperatif dönemde akciğer koruyucu ventilatör rejimleri tercih edilmelidir. Şiddetli solunum yetmezliği olan hastalarda tidal volüm $5-6 \mathrm{ml} / \mathrm{kg}$, peak hava yolu basinci $30 \mathrm{cmH}_{2} \mathrm{O}$ altında ve dakika ventilasyonunun arttırılması solunum hızının arttırılması ile sağlanmalıdır ${ }^{12}$.

Hasta ekstübasyon kriterlerini karşllyyorsa, ameliyathanede ekstübe edilmelidir. Postoperatif bulantı ve kusmayı önlemek için medikal proflaksi önerilmektedir ${ }^{12}$. Ekstübasyon sırasında öksürüğü azaltmak için lidokain, deksmedetomidin ve opioidler gibi medi $\neg$ kasyonlar yapılabilir. Laringeal reflekleri engellemek için ekstübasyon derin anestezi altında yapılmalıdır ${ }^{12-13}$. Ekstübasyon sırasında hastanın ağız ve burun kısmının ıslak gazlı bez veya naylon ile örtülü olması mutlak önerilmektedir. Uyandırıldıktan sonra hastaya mutlaka cerrahi yüz maskesi takılmalıdır ${ }^{14}$.

\section{Postoperatif Dönem:}

Ameliyat sonrasında cerrahi ekip tüm KKE'yi kirli alanda çıkartmalıdır. Tek kullanımlık ekipmanlar, tüm ilaçlar ve malzemeler kontamine kabul edilerek atık kutularına atılmalıdır. Malzemeler temizlenme ve dezenfeksiyon amaciyla sterilizasyona gönderilmelidir. Kan ve vücut sıvısı bulaşları gibi gözle görünür kontaminasyonların temizliği dezenfeksiyondan önce yapılmaktadır. Tıbbi cihazların yüzey temizliği $1 \mathrm{~g} / \mathrm{L}$ klorlu dezenfektanla sağlanmakta, $30 \mathrm{dk}$ sonra durulanmaktadır ${ }^{14}$.

\section{Obstetrik hastalarında anestezi:}

Genel anestezi gereksinimini en aza indirmek için rejyonel anestezi uygulanması önerilir. 
COVID-19'lu gebelerde spinal anestezi tercih edilmelidir ${ }^{12}$. Gebelerde spinal anestezi hazırlığı rejyonel anestezi ve genel anestezi hazırlık kurallarına göre yapılmalıdır. Hasta mutlaka cerrahi maske takılı olmalı, spinal anestezi sonrasında bu maske üzerinden oksijen maskesi yerleştirilmelidir ${ }^{15}$. Spinal anestezi öncesi laboratuar değerlerine özellikle de trombosit değerlerine bakılmalıdır. COVID19 viral enfeksiyonunun anneden bebeğe direk bulaşına dair yeterli kanıt bulunmamaktadır.

\section{Rejyonel anestezi:}

Bazı araştırmacıların, viremik hastalarda merkezi sinir sistemine enfeksiyon bulaştırmanın teorik riskine ilişkin endişeleri mevcuttur. $\mathrm{Bu}$ nedenle nöraksiyel anestezi uygulanmasına karşı uyarıda bulunmuşlardır. Bununla birlikte, insan immün yetmezlik virüsü (HIV) ${ }^{16}$ veya suçiçeği ${ }^{17}$ olan hastalarda spinal anestezinin merkezi sinir sistemi tutulumu ile sonuçlandığını gösteren hiçbir kanıt yoktur. Merkezi sinir sistemi enfeksiyonu riski makul kabul edilse de, COVID-19 hastalarına genel anestezi uygulama riskine karşı dengelenmelidir ${ }^{12}$. Uygun hastalarda öncelikli tercih rejyonal anestezi olmalı ve hastaya mutlaka cerrahi maske takılmalıdır ${ }^{8}$. İhtiyaç halinde oksijen desteği nazal kanül ile uygulanmalıdır.

COVID 19 olgularında rejyonel anestezi uygulaması sırasında: genel anesteziye hazırlanır şekilde hazırlanıp sonra operasyon odasına alınmalıdır. Koruyucu ekipman tam ve eksiksiz giyilmelidir. Hasta mutlaka cerrahi maske giymelidir12. Spinal anestezi için "pencil point spinal iğne" kullanılmasının viral materyalin beyin omurilik sıvısına geçiş riskini azalttığı belirtilmektedir. Ultrason (US), propları ve kılıflarıyla hazır biçimde bulundurulmalıdır. US kullanımı hem başarı şansını arttırması hem de işlem süresini kısaltması amacıyla önerilmektedir ${ }^{1}$. Rejyonel anestezi sirasinda sedasyon uygulanan hastalarda EtCO2 monitörizasyonu mutlaka yapılmalıdır ${ }^{1}$.

Sonuç olarak COVID-19 salgını tüm dünyayı ilgilendiren bir sorun olması nedeni ile de riske en açlk ve doğrudan karşı karşıya olan sağlık sektörünün tüm çalışanları etkilenmiş etkilenmektedir. $\mathrm{Bu}$ nedenle anestezi uygulamaları sırasında, enfeksiyon kontrolü açısından güvenliğin sağlanması gerekir.

Çıkar Çatışması Beyanı: Yazarlar çıkar çatışması olmadığını bildirmişlerdir.

Finansal Destek: Bu çalışma her hangi bir fon tarafından desteklenmemiştir.

Declaration of ConflictingInterests: The authors declare that they have no conflict of

interest.

Financial Disclosure: No financial support was received.

\section{KAYNAKLAR}

1. Li $Q$, Guan $X, W u P$, et al. Early transmission dynamics in Wuhan, China, of novel coronavirusinfected pneumonia. N Engl J Med. 2020; 382: 1199207.

2. Rothe C, Schunk M, Sothmann $P$, et al. Transmission of 2019-nCoV infection from an asymptomatic contact in Germany. N Engl J Med. 2020; 382: 970-1.

3. World Health Organization. Statement on the second meeting of the International Health Regulations (2005) Emergency Committee regarding the outbreak of novel coronavirus (2019nCoV). Published January 30, 2020. Accessed April 8, 2020.

4. Center of Disease Control and Prevention (CDC). Interim Infection Prevention and Control Recommendations for Patients with Suspected or Confirmed Coronavirus Disease 2019 (COVID-19 in Healthcare Settings. 2020. https://www.cdc.gov/coronavirus/2019ncov/hcp/infection-controlrecommendatio.

5. Wong J, Yuan Goh Q, Tan EZ, et al. Preparing for a COVID-19 Pandemic: a Review of Operating Room 
Outbreak Response Measures in a Large Tertiary Hospital in Singapore. Canadian Journal of Anesthesia 2020; 67: 732-45.

6. T.C. Sağlık Bakanlı̆̆ı. COVID-19 Kişisel Koruyucu Ekipman Giyme Çlkarma Talimatı. https://dosyamerkez.saglik.gov.tr/Eklenti/36977,c ovid-19-kişisel-koruyucu-ekipman-giyme-ve cikarma-talimatipdf. Erişim tarihi:Nisan 2021).

7. Karaca AS, Özmen MM, Uçar AD, Yastı AÇ, Demirer S. COVID-19'lu Hastalarda Genel Cerrahi Ameliyathane Uygulamaları. Turkish Journal of Surgery 2020; 36.

8. Dexter F, Parra MC, Brown JR, Loftus RW. Perioperative COVID-19 Defense: An EvidenceBased Approach for Optimization of Infection Control and Operating Room Management. Anesth Analg. 2020;131: 37-42.

9. T.C. Sağlık Bakanlığı. Acil anestezi yönetimi https://covid19. saglik.gov.tr/TR-66164/covid-19acil-anestezi-yonetimi.html. Erişim tarihi: Nisan 2021.

10. Xiangdong C,Yanhong $\mathrm{L}$, Yahong $\mathrm{G}$, et al.Perioperative Management of Patients Infected with the Novel Coronavirus: Recommendation from the Joint Task force of the Chinese Society of Anesthesiology and the Chinese Association of Anesthesiologists. Anesthesiology Newly Published. 2020.

11. Cook TM, El-Boghdadly K, McGuire B, et al. Consensus guidelines for managing the airway in patients with COVID-19: Guidelines from the Difficult Airway Society, the Association of Anaesthetists the Intensive Care Society, the Faculty of Intensive Care Medicine and the Royal College of Anaesthetists. Anaesthesia. 2020 Mar 27..

12. Tang G, Chan AKM. Perioperative management of suspected/confirmed cases of COVID-19. Available from: www.wfsahq.org/resources/anaesthesiatutorial-of-the-week-ATOTW.

13. Brewster DJ, Chrimes NC, Do TB, et al. Consensus statement: Safe airway society principles of airway management and tracheal intubation specific to the COVID-19 adult patient group. Med J Aust. 2020;212 :472-481.

14. Peng PW, Ho PL, Hota SS. Outbreak of a new coronavirus: what anaesthetists should know. British Journal of Anaesthesia. 2020; 124: 497-501.

15. Odor PM, Neun M, Bampoe S, et al. Anaesthesia and COVID-19: infection control. Br J Anaesth. 2020 Apr 8. pii: S0007-0912(20)30200-2.

16. Hughes SC, Dailey PA, Landers D, et al. Parturients Infected with Human Immunodeficiency Virus and Regional Anesthesia : Clinical and Immunologic Response. Anesthesiology: The Journal of the American Society of Anesthesiologists. 1995; 82: 32-7.

17. Brown NW, Parsons APR, Kam PCA. Anaesthetic considerations in a parturient with varicella presenting for Caesarean section. Anaesthesia. 2003; 58: 1092-5. 